\title{
21
}

\section{Recent Logical Inquiries and Their Psychological Bearings}

The American Psychological Association has always given a kindly recognition to the general philosophical interests which many of its members represent, as well as to the more distinctively psychological concerns which properly form the center and the main body of its undertakings. In honoring me, by calling me to fill for the year the office of president, my fellow members have well known that they ran the risk of hearing a discussion rather of some philosophical problem than of a distinctively experimental topic. I, in my turn, am quite unwilling to ignore or to neglect the fact that ours is primarily a psychological association, while I am equally aware that the general student of philosophy is at a disadvantage when he tries to discuss with the productive workers in the laboratories the matters which, as their specialty grows, come to be increasingly their own peculiar possession. Yet a presidential address is properly an opportunity for studying the problems suggested by a comparison of various fields and methods of work. And accordingly, upon this occasion, I propose to discuss some questions that lie on the borderland between psychology and the distinctively philosophical disciplines. These questions in part directly touch

[Reprinted from Psychological Review, 9 (1902): 105-33.] 
undertakings which already occupy a recognized place in the psychological laboratories. In part they seem to me to promise to yield in future still wider opportunities for experimental research than are now open. In any case they are questions of permanent interest, and of increasing importance, which neither the psychologist nor the philosopher can afford to ignore.

I have named my paper a discourse upon 'recent logical inquiries and their psychological bearings.' By the term 'recent logical inquiries,' I mean to refer to two decidedly distinct classes of researches, both of which are today receiving much attention. To the first of these two classes belong researches directly bearing upon the psychology of the thinking process, and upon the natural history of logical phenomena in general. Such inquiries may be called logical, since they are sometimes undertaken by logicians for the sake of their own science, and in any case are suggested by the problems of logic. Meanwhile, studies of this class are obviously also, at least in intention, contributions to psychology. But I wish, in addition, before I am done, to call attention to quite another class of researches, whose psychological bearing is not at first sight so evident. This my second class of recent logical inquiries consists of studies in the comparative logic of the various sciences, and of examinations of the first principles of certain special sciences. I refer here especially to such books as Mach's well-known volume on the 'Principles of Mechanics,' and to all the large literature that has grown up about the problems suggested by the fundamental concepts of the different natural sciences. I place in the same class, moreover, the elaborate and fruitful researches into the foundations of arithmetic, of geometry, and of the Theory of Functions, which are due to such mathematicians as Cantor, Dedekind, Peano, Klein, Hilbert. The last three or four decades have seen an enormous extension of the literature of this type. I include, moreover, in the same class, certain more distinctively philosophical treatises such as Russell's 'Essay on the Foundations of Geometry,' and Couturat's volume on the 'Concept of the Infinite,' and these are but specimens of the class of inquiries in question.

I mention this vast collection of significant studies, not because 
I am in any sense a master in this field of the comparative logic of the sciences, but because, as a humble learner, I have been trying to make my way in some of the plainer of the paths that these recent studies have been opening, and because I hope, by a few wholly inadequate, but at least timely indications, to show upon this occasion that this relatively new comparative study of the fundamental conceptions of various sciences, is full of promise for the psychologist as well as for the logician.

Of the intrinsic importance of this my second class of 'logical inquiries,' there can be, in many cases, no doubt. From the literature of comparative logic to which I thus refer, there is certain to grow, with time, a new science, which I may venture to call a comparative morphology of concepts. This science will occupy a borderland position. In one respect, it will belong to philosophy properly so called. For it will lead to advances in just that critical consideration of the foundations of knowledge which constitutes one principal division of philosophy. Upon the other hand, the new science will be an empirical as well as a reflective doctrine. It will include a critical examination of the history and evolution of the special sciences. And in this respect it will take its place as a contribution to the general history of culture, and will furnish material for the student of anthropology and of social psychology. And, still further, the new science will contribute to the interests of the student both of general and of experimental psychology. For it will set in a new light the empirical problems of the psychology of the intellect. It will define, in new form, issues which the descriptive psychologist must attempt to reconsider. And, as I am convinced, it will present an ample array of problems for the experimental psychologist,-problems which he alone will be able to pursue into some of their deepest recesses. This new science, then, which you and I can hardly live to see very highly organized, but which the whole century now beginning will greatly advance, will offer large ranges of what one may call neutral ground, where philosopher and psychologist, special student and general inquirer, historian and sociologist, may seek each his own, while a certain truce of God may reign there regarding those boundary feuds which these various types of students are prone to keep alive, whenever they discuss with one another the limits of their various territories, and the relative importance of their different tasks. 
II

Two distinct and very large classes of 'logical inquiries' my title is thus intended to bring at once to your attention. My reason for naming them by means of one phrase, and for considering them in one paper, is this: When you examine the first of my two classes of recent inquiries, you find that while much is now doing to advance our knowledge of the psychology of the thinking process, we have to admit that the present state of research in this field is not wholly satisfactory. The general theories about what the place of thought is in the natural history of our minds, and about the special processes of which thinking consists, are numerous; but regarded as psychological theories, they still seem for the most part loose and ill-founded. On the other hand, the special efforts to break paths into the thickets of the psychology of the thinking process by means of experimental research, have so far met with serious obstacles, have often given negative results, and in any case have been confined to the outskirts of the subject. A survey of our first class of recent inquiries will therefore suggest to us the need of looking in new directions for additional sources of aid in the study of the psychology of the higher intellectual processes. In view of this fact it may appear, before we are done, that there is a genuine promise of help towards further advances in this branch of psychology, in case we look for such help to what I have called my second class of recent inquiries in logic. These studies in the comparative logic of the sciences are at once, as I have said, philosophical and empirical studies. They are logical researches regarding the foundations of knowledge. They are also historical reports regarding the way in which our human thinking processes have worked and are working in the world of live thinkers and of socially guided investigations. To call attention, in however feeble or summary a way, to the evidence that is thus attainable regarding the natural history of the thinking process, is a purpose that may justify my necessarily very superficial comments upon this branch of my topic.

\section{III}

And so let me next say something about the first of my two classes of recent inquiries, namely, those that are more obviously and explicitly guided by psychological motives. 
The psychology of the intellect is one of the oldest branches of psychological inquiry. In Greece it began in pre-Socratic philosophy. It became prominent in Aristotle's doctrine. Both Stoics and Epicureans contributed to it. Scholasticism elaborated and modified Aristotle's theories regarding the whole province. Modern philosophy, and in particular the English psychology, began with renewed interest in the problems of this branch of mind. Thus, the psychology of knowledge was long the favored child of the philosophers, at times when the feelings and the more purely volitional aspects of mental life were comparatively neglected in their researches. In a sense this advantage of the intellectual process has continued in recent times. The psychology of association and that of perception have been steadily advancing. Attention, discrimination, and lately memory, have been experimentally studied. But on the other hand, in recent psychology, just the region where, at the outset, the interest of the philosophers was early centered, namely, the region of study of the higher intellectual processesconception, judgment and reasoning-is the very province of psychology where progress, in any exact sense, is nowadays so slow. The difficulty of reducing the problems which, for the psychologist, arise in this region, to any form capable of exact experimental inquiry, is notoriously great, and will of course long remain so. Meanwhile, however, the actual importance which psychological methods have won in the esteem of modern writers, have led to repeated attempts to found reforms in logic upon psychological theories. Numerous are the modern works on logic wherein the psychology of the thinking process is expounded at the beginning of the whole research, or at least is made the basis upon which an author's logical doctrines depend. The great influence of Brentano's doctrine of the process of judgment upon one whole series of logical inquiries in Germany is well known, and is an example of what I mean. The earnestness with which the problem of the nature of the 'impersonal' judgments has been discussed by a large number of modern writers on logic is another example of this subordination of logical to psychological issues. For the doctrine of the 'impersonal' forms of expression is a problem of the psychology of language, and to my mind, interests the pure logician hardly at all.

Meanwhile, if psychological doctrines have thus played a large part in the books upon logic, one can hardly feel surprised to find that, in the present state of the psychology of the intellect, the 
theories about the higher intellectual processes which have been expounded in the logical treatises have been somewhat dishearteningly various and capricious. Concerning the processes of abstraction and conception, certain stereotyped formulas were indeed, until quite recently, pretty constantly repeated. But with the doctrine of judgment, chaos in the textbooks of logic began. Judgment was, so one sometimes said, a process of pure association of ideas, wherein the subject idea recalled to mind by contiguity the predicate idea. But no, said others, it was rather a process of Herbartian apperception, wherein the predicate idea assimilated the subject idea and forced it to fuse with itself so that they became but one idea. On the other hand it was often something much nobler; it was an active process of synthesis, not to be confounded either with mere association or with passive fusion-a constructive process wherein subject and predicate idea came to be connected by certain peculiar mental links. Yet not so; on the contrary, it was a process of analysis, whereby a given whole was divided into parts, and the subject and predicate were the products of this sundering. Or, yet again, it was no union and no sundering of ideas at all, but something quite different-an estimate about the objective value of a connection of ideas. But still once more, it was none of all these things, it was an entirely irreducible act of accepting or rejecting an idea or a complex of ideas; and upon this psychologically irreducible and primal act was founded our very conception of any distinction whatever between the objective and the subjective world. All these things judgment has been in the textbooks, and this, as you well know, is not the end. And all these views have been advanced, upon occasion, as psychological theories about the process of judgment, as theories either verifiable by direct introspection or else deducible from more general doctrines about our mental processes.

In presence of such a variety of opinions, many students interested in the theory of the thinking process have tended, in more recent discussion, to choose one of two opposed directions. Either they have been disposed to relieve themselves altogether of any responsibility for settling the psychological problems, by drawing a technically sharp line between Logic and Psychology, by devoting themselves to the former, and by leaving out of the logical inquire all consideration whatever of the descriptive psychology of thinking; or else, choosing rather the psychological road, they 
have attempted to reduce the problems in question to some shape such as would make possible a more exact introspection of the details of the thinking process by causing these to occur under experimental conditions. The former of these two ways of dealing with the problem of the nature of the thinking process has recently been formally adopted, amongst other writers, by Husserl, in his Logische Untersuchungen. Husserl has vigorously protested against all psychologisirende Logik. Logic, he insists, must go its own way, yet Husserl, in his still unfinished and very attractive researches, yet lingers over the problems of what he now calls the 'phenomenological analysis' of the thinking process, and his farewell, as a logician, to psychology proves to be a very long one, wherein the parting is such sweet sorrow that the logician's escape from the presence of psychology is sure to lead to further psychological complications. As a fact, I cordially accept, for myself, the view that the central problems of the logician and of the psychologist are quite distinct, and that the logician is not responsible for, or logically dependent upon a psychological theory of the thinking process. Yet I am unable to doubt that every advance upon one of these two sides of the study of the intellectual life makes possible, under the conditions to which all our human progress is naturally subject, a new advance upon the other side. I believe in not confounding the tasks of these two types of inquiry. But I do believe that a mutual understanding between the workers will be of great importance; and I feel that we need not discuss at very great length, or insist with exaggerated strenuousness upon the mere separation of provinces in a world of inquiry wherein to-day there are rather too many sunderings.

Meanwhile, as to the other ways of approaching the problem of the nature of the thinking processes, namely the way of attacking them from the side of a more careful application of the methods of recent psychology, that at present, as I have said, is beset with well-known difficultics-difficulties upon which I need not dwell long in this presence. The most important thinking processes do not occur under conditions such as either the subject in the laboratory can casily rcinstate at will, or the experimenter can determine for the subject while the latter is under observation. The thinking processes upon which experimenters have so far carefully worked are therefore artificially simplificd oncs-important, but elementary. The numerous investigations regarding the process of the 
perception of small differences of various types belong here, and constitute, in one aspect, a contribution to the psychology of judgment. The mental reactions upon the presentation of words and phrases, heard or seen by the subject, have been studied by Ribot and by others. Recently Marbe has undertaken to investigate experimentally the psychology of judgment, although under conditions that I have to think by no means very satisfactory. Simple computations, acts of recognition, of estimate, of naming, have also been investigated in various laboratories. But as you know, the positive and assured results of such work have been by no means all that one could wish. Especially notable has been the decidedly negative result of a good deal of this investigation of artificially simplified thinking processes. While, to be sure, the study of the perception of small differences has shown how unexpectedly complex are the psychophysical conditions upon which such judgments depend, the effort in case of even much more complex and intelligent thinking processes to find present in consciousness contents as complex as those of a rational thinker ought to be, has not met, under experimental conditions, with the success that one might have hoped for.

Ribot discovered that in many cases, when one presented to the thoughtful subject a general term whose meaning was somewhat abstract, but nevertheless familiar to him, and when one asked him what mental contents the suddenly presented term directly brought to mind, the answer was simply, 'nothing.' Marbe, dealing with trained subjects, of scientific habits of mind, made them perform and express simple acts of judgment, under experimental conditions, and asked them to observe introspectively the conscious accompaniments of these acts. He found, in general, that the subjective accompaniment of the judgment, apart from the direct consciousness of the very act whereby one gave expression to the judgment, was nothing at all characteristic, and was very often, as in Ribot's subjects, simply nothing at all. The subject in Marbe's experiments was to make a judgment of some intellectual value, but pretty easily accessible to him, regarding a certain presented content; as, for example, he was to choose which one of the two perceived objects had a given character; or he was to answer some other simple question, regarding facts or ideas presented to his attention by the experimenter. He was at once to express this judgment, by word, or by other motor process, as the case might be. 
He was then to report what mental accompaniments the act of judging had involved at the critical moment. The result of the experiments was to show that these well-trained thinkers responded to the situation in question in a mainly reflex fashion. They expressed their discriminations, their translations of Latin phrases, or their other simple intellectual processes, with relatively little difficulty; and all that was characteristic of the conscious process at the moment was that they observed, of course, the expressive act itself, which they chose in a conscious sense no more and no less than one chooses any other complicated reflex act of high grade such as comes to consciousness while it is carried out. For the rest, they sometimes observed fleeting states such as doubt or surprise, and various chance associated images, or suggested motor sensations, of no importance for the understanding of what it is to judge. These accompaniments of the act of judgment were merely individual accidents.

Such negative results have appeared, upon second thought, not very surprising either to Ribot or to Marbe. Ribot points out that most of the connected and significant processes of our life have to be largely unconscious, just because we are conscious only from instant to instant, while we live with reference to relatively far-off results, and while the rational connections of life have to do with long periods of time. The organization of our intelligent conduct is necessarily, he thinks, a matter of habit, not of instantaneous insight. And a complex abstract idea, as Ribot points out, is a 'habit in the intellectual order.' "We learn to understand a concept as we learn to walk, dance, fence, or play a musical instrument. . . . General terms cover an organized latent knowledge which is the hidden capital without which we should be in a state of bankruptcy." Marbe comforts himself for his negative results with the reflection that a 'Wissen' can never be, as a content, itself 'im Bewusstsein.' The subject judging knows, as Marbe maintains, what the act means, but no conscious content directly corresponds to or embodies this knowledge. The only necessary conscious content that is present to the subject corresponds to the outward act, the speech or gesture, whereby the subject expresses his meaning, and this, in Marbe's opinion, sufficiently explains the negative result of his own experiments.

No doubt these comments of Marbe and of Ribot have a good deal of justification so far as concerns their own experiments. On 
the other hand, however, we cannot feel that their experiments were at all well adapted for observing the wealth of our actual thinking processes, because what they studied was not, in most cases, any process by which a thought can come to be built up in our consciousness at all. They could not thus hope to decide how far thought ever can find a peculiar or characteristic place in human consciousness. For what they both examined were relatively reflex processes that express the mere residuum of a mental skill long since acquired by their subjects. Ribot himself thought, and no doubt consciously thought, when he planned his experiments; Marbe thought, when he considered what problem to choose for presentation to his subjects. But the subject (already, in the mentioned cases, a person of relatively high training), had little or no need to think at all in a situation as simple or as familiar in its type as the one in which the experiment placed him. Therefore it was the experimenter and not the subject in whom the process that was to be studied went on. The subject already long since knew how to meet the familiar abstract term, or to translate the simple phrase, or to answer the other plain question. Either this his previous training disposed him to wait passively, upon hearing the well-known word, until he should have some reason to use it himself, or to bring it into connection with his own acts; or else just such training had prepared him (in Marbe's experiments) to accomplish the act whereby one could express a judgment upon the simple problem presented, or could otherwise easily and instantaneously show one's accustomed skill. In no such case was it necessary that any notable intellectual contents of higher grade should come to the subject's consciousness. The mechanism established by long training was ready. It responded as the training determined. Consciousness showed indeed nothing of an abstract thinking process; but then there was no live thought present to show. Ask me "What is the sum of 3 and 2 ?" or "Who was Washington?" and very probably I shall just then not think at all. If I am disposed, under experimental conditions, to respond to your questions, without knowing beforehand what the question is to be, I shall, upon hearing such an inquiry, respond as smoothly as if I were a wholly reflex mechanism. And very naturally I shall then have nothing to report in the way of introspective facts of a thoughtful sort. For I shall respond much as a baggage clerk at a large station calls out the names of cheques, or as a telegraph 
operator writes out his messages while listening to the familiar clicks of the instrument.

To say this is not to make light of experimental methods in their application to the psychology of thought, but is to show that if the problems of the psychology of the intellect are to be prepared for more effective and advanced experimental research in future, the thinking process must first, in some measure, be more fruitfully analyzed than has yet been the case, into elementary processes of a type capable of separate experimental study. On the other hand, the way in which these processes are synthesized into the richer life of concrete thinking must be discovered mainly in an indirect fashion, through an examination of the expressions of thought in the various products of the human intellect, as they appear in language, in social institutions, in the mechanical inventions and constructions which human reason has made, and in the constitution of the sciences themselves-those highest expressions of man's ingenuity. Meanwhile, as I think, a preliminary examination of these very larger expressions of the intellect themselves, may also help us to proceed further than we have yet done in the preparatory analysis of the elementary activities upon which our thought depends, and may enable us thus to open the way towards such an experimental investigation of the conscious aspects of live thinking as just now we lack.

What then is the best means to make such a preliminary analysis of the thinking process into its elements? To analyze thought by means of a study of the phenomena of language has so far been, from Plato's time onwards, the principal undertaking of those who have approached the psychological problems of the intellect from the objective side, that is, from the side of the way in which human thought has outwardly expressed itself. The logicians and the psychologists have joined in a frequent examination of the phenomena of speech. Both types of investigators have sought thus to acquire a knowledge of what the thinking process essentially is. And this sort of inquiry still prospers. A recent logician, Benno Erdmann, has undertaken elaborate studies in this field, studies that have combined the analysis of pathological facts with those experimental researches which he and Professor Dodge have made so well known. From the psychological side, and with vast resources in the way of varied materials, Wundt has also lately prepared his really wonderful volumes on language, working with all the equipment 
of the experimenter, the logician, and the philosopher, but carefully distinguishing the task of this recent book from that of his own earlier treatise on logic. One may say, then, that the psychology of language is indeed in a progressive state. Yet I cannot but hold that the relation of language to the thinking process has been somewhat too exclusively emphasized by many students of the subject. Thought has other modes of expression than through the forms of speech. Language has other business besides the expression of thought. Wundt's book has the merit of emphasizing the close and primary relation of language to the expression of the feelings and to the life of the will. In consequence, Wundt very decidely sets limits to the tendency either to regard the grammatical categories as essentially logical ones, or to use the psychology of language too exclusively as a means for interpreting the psychology of the thinking process. For this very reason his book rather encourages one to look elsewhere for auxiliaries in comprehending the psychology of the intellectual life.

I have thus endeavored to sketch some of the more directly psychological of the recent inquiries into the nature of the thinking process, in order to show why, despite all these various developments, I myself think that the psychologist still has much to learn from researches in other fields than those in which he has so far been most accustomed to seek for help. These other fields are the very ones which are opened by those recent inquiries in the comparative logic of the sciences of which I spoke at the outset.

\section{IV}

Some widespread influence, it is hard to tell exactly what, has led, during the last three or four decades, to repeated, and often seemingly independent and spontaneous, efforts on the part of the students of various special sciences to undertake an examination into the first principles of their own branches of inquiry. The mathematicians say that it was the discovery of errors in certain accepted theorems or proofs of theorems which was the principal motive leading to their own modern desire for an increased rigidity of methods, and an increased clearness regarding their fundamental assumptions. A wide extension of some of their earlier conceptions, such as the conception of a function, resulted, during the nineteenth century, from the natural advances of their science. It 
was found that as such conceptions extended their range of application, theorems to which no exceptions had been known at earlier stages of the science became obviously of restricted application in the new fields thus opened, and often had to be restated altogether. In consequence, proofs of these theorems which had been accepted as valid in earlier stages of the science, were seen, in the light of the enlarged conceptions, to be invalid, or to be capable of rigid statement only through the addition of precise qualifications which had earlier escaped notice. Thus there arose a keenly critical consciousness about what constituted exact statement and rigid proof. Moreover, mathematicians are especially disposed by the work of their science to compare together the results of various and apparently independent sorts of inquiry. Especially is this case when one considers the relations of geometrical and analytical science. At one time geometrical intuition, at another time analytical computation, may lead in the advancement of mathematical knowledge. The question therefore constantly arises, Which of these two sorts of inquiry is the superior in power, or in logical exactness? Such comparisons must lead to constantly renewed self-criticism passed by the science upon itself.

Again, early in the nineteenth century, the constructive imagination of certain geometers of genius initiated an examination of the foundations of Euclidean geometry which has since proved of the utmost importance as a study in the fundamental concepts of all science. Such influences long worked in a comparatively isolated way. Towards the close of the century they combined to bring about a sort of common consciousness on the part of mathematicians regarding the methods that they required of the investigator and of the expounder of mathematical truth. This common consciousness expressed itself not only in the regions where the science was advancing to conquer new territory, but in the study of the oldest, the most fundamental, simple and universally human of mathematical ideas. The concept of number is one of the earliest of human scientific acquisitions; yet it has recently been subjected to a searching logical analysis with decidedly novel and unexpected results, so that nobody can rightly judge what it is to count or to use numbers for purposes of recording measurements, unless he has taken into consideration mathematical discussions that are hardly thirty years old. The various extensions of the numberconcept,-the relation between rational and irrational numbers, the 
relations of number to quantity, the different systems of complex numbers, the conditions logically necessary in order that number systems should be applied to the expression of space-relations,all these topics have been reviewed from the foundation upwards; and the work still goes on. The various actual or possible conceptions of continuity, the exact meaning to be ascribed to the concepts of numerical and of quantitative infinity, the logical position of the conception of an infinitesimal,-all these matters have been reconsidered with a care and a novelty of results which no one can appreciate who has not come into closer contact with at least a few of these researches. And now what I wish especially to emphasize, is that all these analyses, while their direct purpose is logical, inevitably possess a psychological bearing. For they throw light upon the structure which the universally human processes of counting, measuring, comparing and otherwise dealing with continuous magnitudes have always possessed. They define certain of our most fundamental intellectual interests in our world of experience. They therefore not only logically clarify and in so far transform these interests, but they tend to several otherwise hidden aspects of the natural history of these interests themselves.

For instance, the logical prominence which these modern researches in the logic of arithmetic give to our general concepts of serial order, as contrasted with our more specialized quantitative concepts, involve a generalization about the nature of the thinking process that at once has a psychological application. For we learn hereby to distinguish the activities through which we have formed the conception of any ordered series of facts from the processes whereby we have learned to apply this conception in certain important, but decidedly special, cases to the task of measuring magnitudes. The two processes are different, not only logically, but psychologically. The second is a highly specialized application of the other, which is the more primitive and the simpler. The new problem that arises for the psychologist is that of the psychology of our ideas of serial order. The forms in which this problem is to be attacked with fruitful success by the psychologist must be furnished to him by the logician of mathematics. The latter discovers by analysis what concepts of order are fundamental and what ones, logically speaking, are derived; and how the more complex forms of order are related to the simpler. The solution of this logical question is of course primarily not any decision of a ques- 
tion of genesis. But it is the answer to the question, What forms of order, what types of serial arrangement are of the most importance in human thinking about the world of experience? This answer inevitably tells us, however, something about what is universal in the actual constitution of those habits of our organism upon which our thoughts about order depend. It is true then that to ask, What is logically fundamental in our ideas of order? is to ask not a psychological, but a logical, question. But to discover what is logically universal, as the basis of our exact ideas, is to find out a process that must be very widely represented in those organized modes of action of which our thoughts are an inner expression. Hence the result of the logician's analysis, while it cannot be directly translated into a logical theory, is inevitably the setting of a definite problem for the experimental psychologist.

As a fact, the problems of the psychology of the concept of order form a field for experimental research whose importance the whole modern logic of mathematics makes daily more obvious, while the adaptability of the problems for the labors of the experimenter is so obvious as hardly to need lengthy illustration. Psychologically speaking, the importance of the order in which facts are presented to us is illustrated by every case of an inverted letter, by every disarrangement of a familiar temporal or spatial sequence, by every instance of the illegibility even of our own handwriting when seen in a mirror. One of our earliest and principal mental interests is in the serial order of things and in the weaving of various serial orders into systems. But mathematical science is in large part an analysis of ordinal systems. Hence an advance in our analysis of the logical concept of order, and in our knowledge of its range of application, makes possible a more fruitful study of the natural history of thought than would otherwise lie within our power.

In the modern study of the logic of the space-concept, there is again a rich field where the results of the mathematical logicians suggest problems for the psychologist. I have myself been surprised to see how little interest psychologists have generally taken in the space-theories of modern mathematics. There is a remark of Klein, repeated since by a good many writers, to the effect that modern projective geometry, with its non-metrical methods, is rather a description of the properties that are most prominent in visual space, while ordinary geometry, with its quantitative or metrical 
concepts, is rather founded upon our experience of the space of our touch and of our bodily movements. This remark emphasizes what is indeed an obvious fact. One may pass lightly over it, and think little of it. But its significance begins to dawn when one learns something of those logical relations between non-metrical and metrical geometry which Cayley, and later Klein himself, first made prominent. Projective geometry, taken in the abstract, can be developed without the use of any conceptions whatever of metrical relations in space. In other words, projective geometry is a science of spatial order, and not at all of spatial quantity. Cayley and Klein showed how, by the use of certain (once more, very abstract and ideal) assumptions, our ordinary metrical geometry can be made to appear as a highly specialized case of this purely ordinal science. In the light of this consideration, Klein's just cited remark about the contrast between visual space and tactual motor space suggests a very interesting, although a very complex psychological problem about the psychology of the concepts of order and of quantity in their application to space. I suppose that no psychologist would admit that visual space is primarily non-metrical; and, of course, Klein did not mean that it was purely so. For the rest, visual space is obviously related to our consciousness of the results of our movements, and cannot be isolated from them, except by a deliberate abstraction. But, on the other hand, visual space certainly does present to us the facts which projective geometry isolates; while our other space experiences do not directly involve these projective facts at all. But the projective facts, as logical analysis shows, are, when taken by themselves, nonmetrical, while the laws of the metrical facts regarding space are capable of being conceptually defined as very specialized cases of results, under certain ideal conditions, of the laws of a non-metrical space-world. These considerations may not prove to have important results for the psychology of our concepts of order and of measure; but as they stand, they certainly suggest genuine problems for psychological scrutiny. I wonder, then, to find them so little regarded by the psychological students of the space problems.

In a somewhat different direction various contributions to the questions about our consciousness of space have been made, within the last few years, by M. Poincaré, who has here shown, not only all the knowledge of a great mathematical investigator, but also a decided effort to translate his analysis into psychological terms. These contributions of Poincaré, following the results of Lie and 
others, have laid stress upon the relation between our general spatial conceptions and the mathematical theory of 'groups'; and they promise in still another way to bring to pass connections between psychological and mathematical investigations. In view of such developments, I feel that the time is approaching when no psychologist will have a right to try to contribute to a knowledge of our space-consciousness, so long as his own geometrical conceptions are still confined to those of the mathematical textbooks of his early youth. Psychological space theories must be brought into explicit relation with mathematical theories.

\section{V}

But I must hasten from this mention of the merely mathematical investigations to a still more summary reference to similarly analytic work that has been done in other fields of the logic of science. The books of Mach, whose name I have already mentioned, are surely known to many of you. Dr. Paul Carus has proved, as editor and as director of translations, a beneficent aid to our students in this country by making literature of this type widely accessible amongst us. And you surely know the spirit of much of this modern literature of the logic of science. It is characterized, first, by a certain measure of the same sort of critical skill which has made the modern mathematicians so rigid in their methods of proof, and so critical of their first principles. To be sure, outside of pure mathematics, you seldom meet with the degree of rigidity which that science has of late so carefully cultivated; but still the spirit of watchful self-analysis, the freedom from sacred and unquestionable dogmatic presuppositions of all sorts, the willingness to consider fairly the possibility of the opposite of any once asserted proposition, are the common features which characterize Mach, Pearson, Hertz, and the other typical writers of this recent movement. Even as I have been preparing this discussion there has come into my hands the Vorlesungen über Naturphilosophie of Ostwald-a book of whose charm a reading of the first half of the lectures has already convinced me, and whose logical spirit, whatever you may think of its results, is of the most delightful and wholesome. The researches of which such literature is the representative, are characterized by a view of the nature of the thinking process which is closely allied to that which the mathematicians have gradually developed. For one thing, human thought, in the 
view of such modern writers, is not bound by any one definable collection of unquestionable axioms, nor yet limited in its operation by any mysteriously predetermined set of irreducible primal concepts. It is a variable and progressive process that is concerned with the adjustment of conduct to experience. In place of unquestionable axioms, one has therefore, in any science, only relative first principles, resolutions, so to speak, to treat some portion of the world of experience as describable in certain terms. The immediate purpose of any thinking process in a special science is the description of experience, and is not what used to be meant by the explanation of facts. To describe experience is to construct a conceptual model that corresponds, point for point, so far as desired, with the observed phenomena. In order to construct this conceptual model, one has to set about one's work with a definite plan of action, a plan large enough and coherent enough to cover the intended range. One's provisionally assumed first principles, or, as such writers often say, one's postulates, are therefore chosen simply, as expressions of this coherent plan of action. One constructs one's model according to these postulates, compares the results with the facts, and is judged accordingly. Meanwhile, a paucity of elementary assumptions is to be preferred, because science, as a practical activity, loves economy. Such writers use the older forms of the principle of causation either not at all, or as sparingly as they think possible,-their reason being that they are not quite sure what the principle of causation used to mean, and that they are interested only in finding such relations. But causal explanations, as formerly conceived, seem to them to have supposed the true connections of facts to be founded in something behind the scenes, which no experience could ever bring to light. Such writers therefore seem to themselves to be working in a purely positive spirit, as Auguste Comte long ago, although in a much cruder fashion, advised us work. They often, like Mach and Pearson, call themselves anti-metaphysical. Yet, as a fact, all this analysis of the structure of the thinking processes of the special sciences, and of what I have elsewhere called the world of description, seems to me to be not only in no wise inconsistent with an idealistic philosophy, but to be a most fruitful auxiliary to such an idealistic interpretation of the facts of the universe as, in another place, I have had occasion to maintain. But here is no place for considering the philosophical value of such a view of the logic of 
science. What I am here concerned to show is that this effort so to expound the principles of science as to make all the assumed relations between the objects of one's thought overt and exact, rather than occult and inscrutable, relations, leads of necessity to an analysis of the process of thinking which is full of psychological suggestiveness. For a similar reason, this effort to justify scientific theories solely by their success in producing conceptual constructions that correspond in definite and controllable fashion with the phenomena, leads to a sort of practical theory of the business of thinking which closely relates the point of view of the logician to that of the psychologist. For the latter must view the thinking process as one of adjustment to the environment; and he must suppose the mental motives which determine the choice of one rather than another way of thinking to be in the long run determined, as to their natural history, by the success of one method of adjustment as compared with that of another.

In consequence, I maintain that the future study of the psychology of the thinking process will have much to gain from a use of such analyses of ideas and processes as this new science of the comparative morphology of concepts will, as it further develops, bring to light.

\section{VI}

My hastily-made catalogue of the types of researches which belong to the second of my two classes of recent logical inquiries is thus, within its present very narrow limits, completed. I must still try briefly, however, to lay stress upon a very important general feature of the thinking process which all these recent researches, whether in the specially mathematical field or in the wider field of the logic of the various natural sciences, seem to have brought to clearer light. So long as logicians were largely confined in their researches to results derived from the analysis of language, the problems which they could hand over to the psychologist were principally the classic, but as I think, relatively fruitless problems, to which Ribot's and Marbe's experimental researches have been devoted-such problems as, What has one in mind on hearing an abstract word pronounced? or, What happens in my mind when I judge that $\mathrm{A}$ is $\mathrm{B}$ ? We have already seen that the modern mathematical researches have prepared for the psychologist a large col- 
lection of relatively new problems relating to our consciousness of the types of serial order, and relating also to the way in which this consciousness of order is linked to our ideas of quantity, of space and of continuity in general. Many of these problems have assumed, in modern mathematical researches, decidedly instructive forms, which are now nearly if not quite ready for experimental study. But the problems which modern logical research is preparing for the psychologist are by no means limited to these. Let me call attention then to another range of problems of a very complex character, but of a type especially likely to receive, I think, ere long, a form suited to novel experimental researches.

Psychologists have already elaborately studied, in the laboratories, our consciousness of the differences between presented objects of various sorts. But a difference between two sensations, or intervals, or other presented facts, is a matter rather of perception than of more elaborate thought. We judge such a difference indeed; but the judgment occurs as a sort of more or less swift or deliberate reflex, subject to no conscious logical principles, except those implied in every least effort to attend to the facts presented, and to report accordingly. Even in such an effort, however, there appears one element that, in the life of our more familiar and complicated thinking, assumes extremely varied and important forms. The subject in a series of experiments upon just observable differences is obliged to report whether two objects appear to him to differ or not to differ in an assigned respect. Upon this side his act of judgment includes what one may call the 'yes' and 'no' consciousness, the decision as between alternatives, the selection or suppression of a certain possible response to an object. But the 'yes' and 'no' consciousness is one that is of course not limited to the case of observing small differences, but that has applications wherever we are able to judge; and one of its most important applications appears whenever we not only observe the differences of objects, but, in some more elaborate way, classify objects. Two objects, such for instance as a triangle and a circle, are in two such different classes for us (when we do judge them as figures of different classes), not merely because we observe that they are for us different in shape, but because, in the presence of one of them we are disposed, in view of our geometrical training, and even of our purely popular habits of thought and speech, to make certain responses, to perform certain deeds, which, in the presence of the other object we should, if these deeds were suggested, suppress, 
reject, inhibit, as unfitting, absurd, untrue. In presence of the circle we do not only tend to follow its contour by means of certain eye movements, and to have suggested to us certain names, memories, and aesthetic impressions; but, if we are thinking about circles we consciously accept certain of our suggested motor responses in presence of the circle, as adapted to express what it means for us, and how it is related to the rest of our life. Some of these very responses to which, in presence of a circle, we thus, so to speak, say 'yes' are amongst the ones to which, in presence of a triangle, we say 'no' in case there then arises any suggestion of our making them. Our customary summary expression of the results of many such acceptances and rejections of fitting reactions in the presence of circles and triangles takes the form of saying that 'no circle is a triangle.' This assertion is of course not the same as the assertion that our representative ideas of circle and triangle are different ideas. One's idea of a Frenchman differs from that of a dancing master. But it is absurd to say that because one is a Frenchman he cannot be a dancing master. Our assertion about circle and triangle is that they are not merely different, but belong to mutually exclusive classes. And we define for ourselves this latter fact of the mutual exclusion of the classes by means of a series of processes in which the conciousness of presented or remembered differences is bound up with the 'yes' and 'no' consciousness in a fashion that the logicians and psychologists of all ages have attempted to unravel, and that the psychologists, at least, have failed to discuss with finality, just because they have so little studied the 'yes' and 'no' consciousness, either in itself, or in its relation to our consciousness of difference.

As for the logicians, with their Eulerian diagrams, and their more recent and exact symbolic notations, they have indeed done much to clarify the more formal aspects of the conceptual relations involved in exclusions and negations; but, as Professor Ormond's paper on the place of the negative in logic showed to this association some years since, the questions here involved are amongst the most delicate and fundamental known to thought, and they are not yet closed issues. What, then, is the precise relation of the consciousness of difference to the consciousness of negation, or of mutual exclusion? Both logicians and psychologists need to study this problem more thoroughly.

But now it is just here that the modern reëxamination of the principles of the various sciences has been enlarging our ideas of 
the importance of the function of what I have called the 'yes' and 'no' consciousness in all our exact thinking. When I first heard about the logic of science, I was told by my teachers that the stage of a science in which it made much of classifications was a relatively imperfect stage. A science, I was told, passed to a higher stage when it learned to substitute explanations for classifications. And its explanations, in their turn, became exact whenever they passed to the highest stage of scientific knowledge, where they became quantitative. Quantity, then, was a concept of a rather mysterious dignity; but it certainly belonged to some very lofty level of thinking, where mere classifications were no longer in question. When one reached this lofty level science became mathematical, and the goal was near.

But nowadays, our new comparative logic of the sciences seems to put this whole matter in a new light. The ideal of exact special science is still mathematical, and will always remain so. But then, for one thing, mathematics, for the enlightened, is no longer merely the science of quantity, but is rather the science of exactly definable relationships of all types. Quantity itself, however, appears, in this new logic, as a conception whose properties and laws, in all the numerous branches of the science of the different kinds of quantity, are definable only in terms of the properties of certain manifolds, or complexes of ideal objects, which are called numbersystems. The number-concept, which, as I before pointed out, is for the modern mathematician very prominently an ordinal concept, has become, in its various modern forms, something more general, as well as logically more fundamental, than the concept of quantity. Our exact knowledge of the laws of quantity thus tends, more and more, to appear as founded upon our knowledge of the laws of number, the latter being deeper and more universal. The result is the tendency towards what Klein has called the Arithmetisirung of mathematical methods. Now this Arithmetisirung implies in part, making prominent, as I pointed out earlier in this paper, the ordinal concepts. But it also implies giving a prominence to exactly defined classifications which I suppose has never before been known in the history of science.

Our knowledge of number-system is, in very large measure, a knowledge that there are, in each system, these and these classes of numbers, and that of every number in one of these classes one can assert what one must deny of every other number in the system Dedekind's famous and epoch-making definitions of the 
irrational numbers as corresponding to the totality of the classifications or Schnitte that one can make in the series of rational numbers, is one brilliant instance amongst many of the way in which classifications have become important in modern exact science. Another instance is Georg Cantor's definition of the grades, or dignities, the Machtigkeiten of infinite assemblages of objects. The discovery of this new concept by Cantor seems to me one of the most brilliant feats of constructive imagination in recent times. It has enriched mathematics, and will enrich future philosophy, with wholly new views of the problem of the infinite. Yet it turned upon a beautifully simple application of an exact principle of classification. Modern algebra, in the conception of what are called 'domains of rationality,' has again used an obvious and fundamental principle of classification, whose application to systems of numbers is very vast, and whose value in very various sorts of problems appears to be immeasurable. The most modern researches into the principles of geometry, and of the other exact sciences, in their efforts to find a sufficient and closed system of mutually independent first principles, have shown how much is gained by exactly classifying the ranges, or domains, to which various principles can be said to apply. Even the single principles, taken by themselves, appear, when thus examined, to be simply classifications of facts. Thus the principle that any two points in a space determine one straight line, while two straight lines can have but one point in common, is for certain purposes best stated as a classification of the points of space. The points namely are such that, if you choose at random any two of them, these two determine one class of points such that every point in space either belongs or does not belong to that class, while no two classes so determined have more than one point in common. Thus stated, the principle regarding straight lines and points appears as it ought to appear; namely, it appears as no self-evident axiom, but as a surprising and even baffling property of the points in space, and so as an arbitrary fact of our spatial experience. It is as if you said: "There is a nation of men somewhere such that any two men in that nation belong to one exclusive club, to which every other man either does or does not belong, while no two such clubs have more than a single member in common." Such a nation would have a strange sort of club-life. But just as such an assemblage are the points in space.

Classification from such a point of view reigns then everywhere on the highest level of cxact science. Sharp classification is the goal 
as well as the beginning of the thought that gets embodied in the special sciences. To say 'yes' or 'no' to the question: "Does this object belong or does it not belong, for this purpose, to this collection of objects?" is the last as well as the first task of the human thinker in all his dealing with particular facts. Now the logical interest of this generalization about the nature of science lies in the consideration that, from this modern point of view, for which the special sciences, as you remember, are descriptions of phenomena, all our valid explanation of facts, just so far as they are valid, all our knowledge of the laws of nature, all our quantitative insight into things must be reduced merely to such classifications of facts, and to serially ordered systems of such classifications. Of such materials our conceptions of what I have called our world of description must consist. One modern writer has explicitly made this very generalization. I refer to Mr. A. B. Kempe, in his paper on the 'Theory of Mathematical Form.' Mathematics, according to Mr. Kempe, who illustrates his notion in a very varied way, is purely a science of exact classification, and is nothing else. It defines the relations of objects and systems of objects by classifying certain of these objects, or certain pairs, triads, or other groups of these objects, by placing certain of them together, and by distinguishing them from other objects or assemblages of objects. Thus, according to Mr. Kempe, one studies geometry in a strict logical order by beginning with the conception that the points of space are, as mere points, undistinguished one from another. One then goes further and notes that not only all points, but all pairs of points in space, may be regarded as undistinguished from one another, so long as you ignore the notions of direction and distance. One next observes, however, that if one takes account of triads of points, one has forthwith a classification of such triads, because all collinear triads of points are distinguished from all noncollinear triads. Upon the basis of this primal classification, as Kempe holds, all the rest of geometrical knowledge can be built up by adding further classifications as new principles are introduced. Every new principle means merely a new classification. And this procedure, as Kempe holds, is typical of the processes of exact thought everywhere. Science, then consists altogether of classifications.

Now what I want to point out is the enormous importance that such considerations give to the function which, in the life of our thinking, I have called the 'yes' and 'no' consciousness. This, I have 
said, is the consciousness wherein we are aware of accepting or inhibiting certain acts-acts through which we treat two or more objects as belonging to one class, or as belonging to classes that exclude each other. The contrast of $\mathrm{X}$ and not- $\mathrm{X}$ is always a product of the working of such a 'yes' and 'no' consciousness. Now I have said that psychologists have too much neglected the closer study of the 'yes' and 'no' aspect of consciousness. Psychologically speaking, it is that aspect of our mental life which accompanies our attitudes of readiness to perform certain deeds, and of attendant readiness to inhibit other deeds. Here then is a place where the modern logical inquiries counsel the psychologist to undertake a more careful study.

As a fact, classifications depend, for us, upon inhibitions, and upon becoming conscious of our inhibitions, and also upon bringing to notice the positive motor tendencies that are in us correlative to these inhibitions. Those who have studied abstract ideas as Ribot has done, or judgments as Marbe has done, have therefore attacked the problems of the thinking process at the wrong end. They have tried to examine the corpse of a dead thinking process. They have found little left but a reflex act. Live thinking is the process of classifying our objects by suppressing, in their presence, certain of our possible motor acts, by welcoming, emphasizing, or letting go certain of our other acts, by becoming aware, somehow, i.e., in some conscious terms, of these our positive tendencies and inhibitions, and by them regarding the objects in the light of the deeds that thus we welcome or suppress.

The most promising problem about the whole thinking process which is thus suggested to the psychologist may then be defined as this: "In what way, to what extent, and under what conditions, do we become conscious of our inhibitions?" Plainly the negative principle in consciousness, the Geist der stets verneint, is the constant accompaniment of all our higher, our organized, our thoughtful activities. It is the principle which makes exact classifications possible. And descriptive thought, in the light of these modern researches, means exact classification, and means nothing else so much. It is by contrast with our inhibitions that our positive motor processes get their precise conscious definition, as inhibitions of inhibitions, as tendencies to act by means of overcoming opposing considerations, and as assertions that are at once coordinate with, and opposed to, denials. Our abstract ideas are products of such an organized union of negative and positive tendencies. We can there- 
fore understand the psychology of live thinking processes only in case we understand when, how far, and under what conditions, inhibition becomes a conscious process.

But now the psychology of the inhibitory processes-how vast a range of interesting phenomena, and how imperfectly explored a territory, does not this name suggest to us all? The world of the phenomena of primitive tabu, how fascinating it seems! Yet with tabu human thought about certain of the exact classifications, both of conduct and of truth, would seem to have begun. The pathology of our inhibitory consciousness, how interesting its complications-how important clinically-how significant from the humane point of view! Some years since, in a paper on the case of John Bunyan, I tried to present to the members of this Association an instance of the descriptive psychology of an experience largely made up of pathological inhibitions, occurring in the early manhood of a great genius. You all know how rich is the clinical material for the study of such cases. But the experimental psychology of the consciousness inhibition-here surely is another extensive, accessible, and comparatively much neglected, and at the same time perfectly definite and promising field of work. I have now tried to show you that modern logical inquiries, in emphasizing the central significance that the process of classification possesses in all grades of our thought, have made more evident than ever that upon an understanding of the psychology of inhibition must depend a great deal of our further advance in a knowledge of the psychology of the thinking process.

I conclude then by urging upon my fellow members (I) the problem of our inhibitory consciousness and (2) the before-men-. tioned problem of the psychology of our ordinal concepts, that is, of our consciousness of ordered series of objects, as the two great tasks that are set before the students of the psychology of the thinking process by the results of modern logical inquiry.

If anything that I have said shall tend to further the mutual understanding between workers in psychological and in logical research, I shall be amply repaid for my efforts in trying thus to state to you something of what I see in the present situation of logical inquiry; while you, I hope, may in that case be not wholly unrepaid for the tediously abstract and lengthy road over which, by your kindness, I have been privileged to lead you. 